\title{
Case report. Een patiënt met flankpijn na spontane graad III-nierlaceratie bij NOAC-gebruik
}

\author{
Eelco R. P. Collette ${ }^{1}$ Antonia W. T. M. Roelofs ${ }^{1}$ Peter A. Stroomberg ${ }^{2}$
}

Published online: 11 January 2019

(c) The Author(s) 2019

\section{Samenvatting}

Een spontane graad III-nierlaceratie is een zeldzaam verschijnsel. Veelal treedt een nierlaceratie op na een trauma of bij een niertumor. Wij beschrijven een patiënt met een spontane graad III-nierlaceratie bij NOAC-gebruik, zonder luxerend moment of aanwijsbare oorzaak. Deze patiënt gaf bij herhaling aan geen val, trauma of mishandeling te hebben doorgemaakt. Zowel de initiële CT-scan als de controlescan toonden geen aanwijzingen voor een niercarcinoom, angiomyolipoom of obstruerend moment.

Trefwoorden nierlaceratie $\cdot$ NOAC $\cdot$ coiling $\cdot$ American Association for the Surgery of Trauma (AAST)

\section{Case report. A patient with flankpain based on a spontaneous grade III kidney lesion with NOAC use}

\begin{abstract}
A spontaneous grade III kidney lesion is a rare phenomenon. The cause of a kidney laceration is often a trauma or a kidney tumor. We describe a case of a patient with a spontaneous grade III kidney lesion with NOAC use, with no demonstrable luxating moment or cause. The patient repeatedly stated that she didn't experienced any fall, trauma or abuse. Both the initial CT scan and the control scan showed no evidence of a renal carcinoma, angiomyolipoma or obstructing moment.
\end{abstract}

Keywords Renal laceration $\cdot$ NOAC $\cdot$ Coiling $\cdot$ American Association for the Surgery of Trauma (AAST)

\section{Introductie}

Een niertrauma is in $90-95 \%$ van de gevallen stomp en in $5-10 \%$ penetrerend. In 1-33\% van de gevallen worden bij het trauma bloedvaten geraakt. Iatrogene schade kan zich voordoen tijdens abdominale chirurgie. Een spontane laceratie is zeldzaam en is in de literatuur zelden beschreven [1-9]. De American Association for the Surgery of Trauma (AAST) renal injury scale is het meest gebruikte classificatiesysteem voor niertrauma, en maakt een indeling in graad 1-5 [6, 10] (tab. 1). De ernst van het trauma wordt beoordeeld aan de hand van de diepte van de parenchym-

Eelco R. P. Collette

eelco@collette.nl

afdeling Urologie, Rijnstate Ziekenhuis, Arnhem, Nederland

2 afdeling Radiologie, Rijnstate Ziekenhuis, Arnhem, Nederland schade en de mate waarin het urineverzamelsysteem en de niervaten bij het letsel betrokken zijn.

Een niertrauma dient volgens de ABCDE-traumaregels te worden benaderd. Hierbij is van belang de aard van het trauma te bepalen en de voorgeschiedenis uit te vragen, waarbij gedacht kan worden aan nierchirurgie en afwijkingen, zoals een UPJ-stenose, een niersteen of niercysten. Bij het lichamelijk onderzoek wordt gelet op huidletsel, hematomen, flankpijn, een palpabele massa, hematurie en een eventuele ribfractuur. De urineanalyse zal uitsluitsel geven over microscopische hematurie. Indicaties voor anvullend radiologisch onderzoek zijn penetrerend trauma (zoals een steekwond) of een stomp trauma met macroscopische hematurie [1, 2]. Een patiënt met graad 1-4-niertrauma na een stomp trauma die hemodynamisch stabiel is, kan worden behandeld met observatie, bedrust, infuus en antibiotica. Dit beleid is ook van toepassing bij een stabiele patiënt met graad 1-3-niertrauma na een penetrerend trauma. Chirurgische exploratie is aangewezen indien de patiënt hemodynamisch instabiel is, bijkomend darm- of vaatletsel 
Tabel 1 De American Association for the Surgery of Trauma (AAST) renal injury scale [6, 10]

\begin{tabular}{ll}
\hline graad & beschrijving \\
\hline 1 & een contusie of stabiel subcapsulair hematoom, zonder laceratie \\
2 & een stabiel perirenaal hematoom met een corticale laceratie $<1 \mathrm{~cm}$ zonder urine-extravasatie \\
3 & een corticale laceratie $>1 \mathrm{~cm}$ zonder urine-extravasatie \\
4 & een corticomedullaire laceratie tot in het verzamelsysteem of een vasculair trauma van de renale arterie of vene \\
5 & multipele diepe laceraties oftewel een shattered kidney, of trauma van de renale vaatsteel of avulsie van de vaten \\
\hline
\end{tabular}

heeft, een pulserend hematoom of een graad 5-letsel. Een patiënt met een actieve nierbloeding, maar zonder overige indicaties waarvoor onmiddellijke chirurgische exploratie geïndiceerd is, kan door middel van radiologische interventie met embolisatie worden geholpen [1,2]. Na een nietchirurgisch beleid kan een late bloeding, aanhoudende urinelekkage en een perirenaal abces ontstaan. Ook een AVfistel, een urinefistel, hydronefrose, pyelonefritis, een niersteen en hypertensie zijn beschreven bij de graad 3-4-letsels $[1,2,7]$.

Het advies is om de patiënt ongeveer drie maanden na het trauma te controleren door middel van lichamelijk onderzoek, urineonderzoek, nierfunctiebepaling, bloeddrukmeting en, op indicatie, radiologische beeldvorming. Indien sprake is van koorts, flankpijn of een dalend hemoglobinegehalte is herhaling van beeldvormend onderzoek geïndiceerd $[1,2]$.

\section{Casus}

Deze casus betreft een 78-jarige vrouw met flankpijn, die zich midden in de nacht presenteert op onze Spoedeisende Hulp na een verwijzing door de huisartsenpost. De voorgeschiedenis vermeldt hypertensie, atriumfibrilleren, een open cholecystectomie en een Nissen-fundoplicatie in verband met een hernia diaphragmatica. Zij heeft nooit eerder een uroloog bezocht of nierchirurgie ondergaan. Zij gebruikt Rivaroxaban $1 \mathrm{dd} 20 \mathrm{mg}$ en digoxine $1 \mathrm{dd} 0,0125 \mathrm{mg}$. De sociale status vermeldt een actieve vrouw, die in de bloemenzaak van haar kleinzoon helpt. Op het moment van presentatie heeft zij gedurende 12 uur een spontane, continu zeurende flankpijn rechts. Zij heeft geen mictieklachten of klachten passend bij een urineweginfectie, geen hematurie of koliekaanvallen. Zij heeft normale ontlasting gehad, zonder bloed- of slijmbijmenging, tevens geen pijn op de borst, geen hoestklachten of koorts. Zij geeft aan geen trauma, val of mishandeling te hebben doorgemaakt. Patiënte bevestigt dit bij herhaling, ook zonder bijzijn van de familie. De bloeddruk is $95 / 60 \mathrm{~mm} \mathrm{Hg}$, de hartslag 88 slagen per minuut bij een saturatie van $92 \%$. Bij het lichamelijk onderzoek zien wij een niet zieke vrouw met matige pijn, zonder hematoom in de flank of ander uitwendig letsel, zonder afwijkingen aan hart en longen. Het abdomen is bol met minimale peristaltiek, wel hypertympanisch en drukpijnlijk, maar niet geprikkeld. Er is slagpijn in de rechternierloge. Het bloedbeeld is als volgt: leukocyten $11 \times 10^{*} 9 / \mathrm{L}$, CRP $2 \mathrm{mg} / \mathrm{L}$, kreatinine $114 \mathrm{umol} / \mathrm{L}$, GFS 40 (CKD-epi), INR 1,1, APTT $35 \mathrm{sec}$ en PTT $39 \mathrm{sec}$. Het hemoglobinegehalte is bij binnenkomst $8,5 \mathrm{mmol} / \mathrm{L}$ en drie uren later $7,7 \mathrm{mmol} / \mathrm{L}$. Op een buikoverzichtsfoto zien wij uitgezette dunnedarmlissen en maagdistensie. Gezien het klinisch beeld met initieel de verdenking op een ileus wordt een CT-abdomen vervaardigd, die aan de rechternier een actieve arteriële bloeding ter plaatse van de onderpool laat zien met het beeld van een ileus en tevens een groot retroperitoneaal perirenaal hematoom. Er wordt geen ossaal letsel gezien en ook geen obstruerend ureterconcrement. Er zijn slanke ureteren en goede contrastpassage. Hierop wordt een katheter à demeure geplaatst, waarbij heldere urine wordt geconstateerd.

De NOAC's worden gestaakt. Zij krijgt een neus-maagsonde in verband met het ileusbeeld en wordt met spoed aangemeld voor een radiologische interventie voor diagnostiek en eventuele behandeling. Vlak voor de procedure wordt patiënte hemodynamisch minder stabiel. Tijdens de procedure wordt de actieve arteriële nierbloeding ter plaatse van de onderpool bevestigd en behandeld met coiling. Na de procedure wordt patiënte op de intensive care opgenomen ter observatie. De behandeling bestaat uit cefuroximantibiotica en pijnbestrijding door middel van paracetamol en morfine. Tevens krijgt zij veel infuusvloeistof toegediend. De uren daarna is zij hemodynamisch instabiel en het hemoglobine daalt van 7,0 naar $6,3 \mathrm{mmol} / \mathrm{L}$. Zij wordt respiratoir insufficiënt waarvoor zij een non-rebreathingbehandeling krijgt. Er ontstaat een nierfunctiestoornis met een GFS van 29. Door de behandeling wordt patiënte stabiel en kan zij na twee nachten overgeplaatst worden naar de verpleegafdeling. De nierfunctie normaliseert en het hemoglobine blijft stabiel rond de $6,0 \mathrm{mmol} / \mathrm{L}$. Haar voedsel- en vochtintake komen op gang en na een totale opnameduur van negen dagen volgt ontslag naar huis.

Twee maanden na de laceratie volgt ter controle een CTscan van het abdomen met contrast. Deze toont geen aanwijzingen voor een niercarcinoom, angiomyolipoom of obstruerend moment, waarmee deze als oorzaken van de laceratie definitief worden uitgesloten. De rechternier toont een niet-gevasculariseerde onderpool, een bekende status 

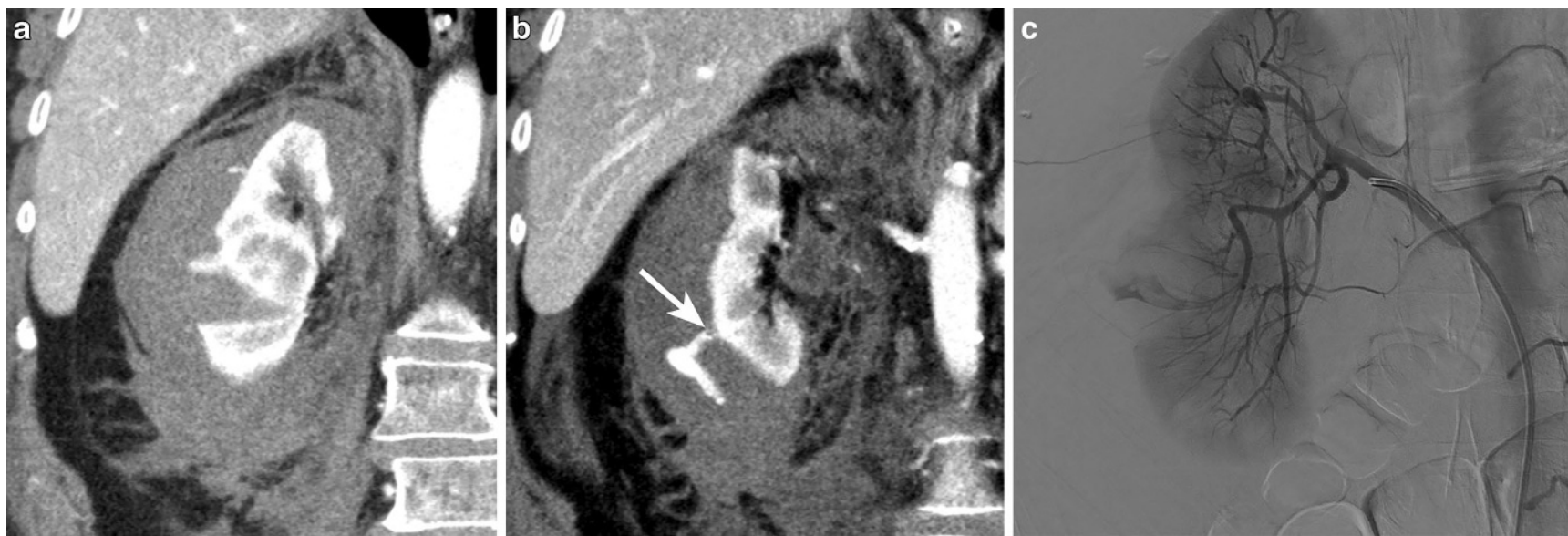

Figuur 1 a CT-abdomen met IV-contrast, gescand in de arteriële fase. Beeldfragment van een coronale coupe. Er is een laceratie zichtbaar in de onderpool van de rechternier met rondom een groot hematoom. b In dezelfde contrastfase is contrastextravasaat zichtbaar ter plaatse van de laceratie, passend bij een actieve arteriële bloeding (pijl). c Angiografie van de rechternier, waarbij de arteriële bloeding in de onderpool van de rechternier bevestigd wordt. Aansluitend is overgegaan tot coiling

na coiling. Tevens is perirenaal rechts een afgekapselde vochtcollectie zichtbaar, passend bij oud hematoom. Negen maanden na het voorval laat een CT-scan een evidente afname van het subcapsulair hematoom van de rechternier zien, met een focaal defect in de aankleuring ter plaatse van de onderpool rechts, zonder dilatatie van het kelk- en bekkensysteem (fig. 1).

\section{Beschouwing}

Wij beschrijven een patiënt met een spontane graad IIInierlaceratie bij NOAC-gebruik, zonder luxerend moment of aanwijsbare oorzaak. Differentiaaldiagnostisch kan er bij een nierlaceratie gedacht worden aan een stomp of scherp penetrerend trauma, zoals een val, mishandeling of messteek. Er kan ook gedacht worden aan reeds bekende factoren, zoals recente nierchirurgie, dialyse of een bekende UPJ-stenose. De meest voorkomende oorzaak van een spontane nierbloeding is een niertumor (61\% van de gevallen). Binnen deze categorie komt een angiomyolipoom of een niercelcarcinoom (ongeveer de helft van de gevallen) het meest frequent voor. Een vasculaire ziekte is de daaropvolgende meest voorkomende oorzaak (17\%), met binnen die categorie polyarteriitis nodosa als meest prevalente [11]. Bij verdenking op een nierbloeding is de CTscan de voorkeursmethode voor de diagnostiek. Een metaanalyse uit 2002 toont aan dat een echografie van het abdomen bij $56 \%$ van de patiënten een bloeding aantoonde. Bij een CT-scan werd de bloeding bij alle patiënten aangetoond $(100 \%)[11]$.

\section{Conclusie}

Bij deze patiënte is sprake van een spontane graad III-nierlaceratie bij NOAC-gebruik, zonder luxerend moment of aanwijsbare oorzaak van de laceratie.

Open Access This article is distributed under the terms of the Creative Commons Attribution 4.0 International License (http:// creativecommons.org/licenses/by/4.0/), which permits unrestricted use, distribution, and reproduction in any medium, provided you give appropriate credit to the original author(s) and the source, provide a link to the Creative Commons license, and indicate if changes were made.

\section{Literatuur}

1. Kitrey ND, Djakovic N, Kuehhas FE, Lumen N, Serafetinidis E, Sharma DM. EAU guideline on urological trauma. Update 2018. Beschikbaar via https://uroweb.org/guideline/urological-trauma. Geraadpleegd op 24 feb 2018.

2. Summerton DJ, Kitrey ND, Lumen N, Serafetinidis E, Djakovic N, European Association of Urology. EAU guidelines on iatrogenic trauma. Eur Urol. 2012;62(4):628-39.

3. Baverstock R, Simons R, McLoughlin M. Severe blunt renal trauma: a 7-year retrospective review from a provincial trauma centre. Can J Urol. 2001;8(5):1372-6.

4. Meng MV, Brandes SB, McAninch JW. Renal trauma: indications and techniques for surgical exploration. World $\mathrm{J}$ Urol. 1999;17(2):71-7.

5. Bruce LM, Croce MA, Santaniello JM, Miller PR, Lyden SP, Fabian TC. Blunt renal artery injury: incidence, diagnosis, and management. Am Surg. 2001;67(6):550-4. discussion 555-6.

6. Moore EE, Shackford SR, Pachter HL, McAninch JW, Browner $\mathrm{BD}$, Champion HR, et al. Organ injury scaling: spleen, liver, and kidney. J Trauma. 1989;29(12):1664-6.

7. Goffette PP, Laterre PF. Traumatic injuries: imaging and intervention in post-traumatic complications (delayed intervention). Eur Radiol. 2002;12(5):994-1021. 
8. Serafetinides E, Kitrey ND, Djakovic N, Kuehhas FE, Lumen N, Sharma DM, et al. Review of the current management of upper urinary tract injuries by the EAU Trauma Guidelines Panel. Eur Urol. 2015;67(5):930-6.

9. Sujenthiran A, Elshout PJ, Veskimae E, MacLennan S, Yuan Y, Serafetinidis $\mathrm{E}$, et al. Is nonoperative management the best first-line option for high-grade renal trauma? A systematic review. Eur Urol Focus. 2017 May 29. Epub ahead of print.

10. Ramchandani P, Buckler PM. Imaging of genitourinary trauma. AJR Am J Roentgenol. 2009;192(6):1514-23.
11. Zhang JQ, Fielding JR, Zou KH. Etiology of spontaneous perirenal hemorrhage: a meta-analysis. J Urol. 2002;167(4):1593-6.

Eelco R.P. Collette aios urologie

Antonia W.T.M. Roelofs uroloog

Peter A. Stroomberg aios radiologie 